\title{
ESTIMACIÓN DE LA DEMANDA NACIONAL DE UN TRACTOR DE BAJA POTENCIA
}

\author{
Moltoni, L. A. ${ }^{1} \&$ Pozzolo, O. R. ${ }^{1}$
}

\begin{abstract}
RESUMEN
Si bien durante los últimos años se ha evidenciado un importante incremento en la producción nacional de maquinaria agrícola, la provisión de tractores sigue teniendo una participación importante de equipos extranjeros. Específicamente en lo que hace a tractores de baja potencia, la demanda es satisfecha casi en su totalidad por importaciones, existiendo a su vez una fuerte presencia de equipos usados. El objetivo del presente trabajo es estimar la demanda de un tractor de baja potencia en la Argentina. Para la realización de este estudio se utilizó como fuente el Censo Nacional Agropecuario del 2002 (CNA02) y la base de datos de Maquinaria Agrícola Argentina (MAA) confeccionada por Pozzolo et al. (2008). Según el análisis realizado, la demanda para este tipo de tractores oscilaría entre 40 y 80 unidades en las actuales condiciones de mercado. La región de Cuyo aparece como la mayor demandante seguida por Buenos Aires, asociada a los cinturones hortícolas.

Palabras clave: maquinaria agrícola, industria nacional, desarrollo local, sustitución de importaciones.
\end{abstract}

\section{SUMMARY}

\section{Demand estimation of a low power tractor in Argentina.}

Even though during the last years the national production of agricultural machinery has grown, tractors are mainly made abroad. Regarding to low power tractors, the local demand is satisfied by imported or used equipments. The aim of this study was to estimate the demand of a low power tractor in Argentina. For that purpose, the National Agricultural Cense Data was used in addition to the Argentinean Agricultural Machinery data base (AAM). According to this research, the demand for this specific equipment would be between 40 and 80 units. These results would be valid if we

1.- Instituto de Ingeniería Rural - Centro de Investigaciones de Agroindústria - Instituto Nacional de Tecnologia Agropecuária. C. C. 25. (1712) Castelar, província de Buenos Aires. email: lmoltoni@cnia.inta.gov.ar Manuscrito recibido el 27 de diciembre de 2012 y aceptado para su publicación el 22 de febrero de 2013 
considered the current market conditions and if no credit policy was applied. The largest demand would be located in Cuyo. The second one would be Buenos Aires. This last demand would be related to horticulture labours.

Key words: National industry, agricultural machinery, local development, import substitution.

\section{INTRODUCCION}

La producción de maquinaria agrícola forma parte de las industrias de insumos y bienes de capital proveedoras del agro, conformando una fase fundamental de la mayor parte de los subsistemas agroalimentarios argentinos. La industria nacional de maquinaria surgió muy tempranamente en torno a pueblos de la región pampeana, con fuerte concentración en el sur de la provincia de Santa Fe. El aprovechamiento de las ventajas comparativas naturales y la mecanización, por medio de la incorporación de maquinaria importada, operaron como estímulo para el desarrollo de este sector de la industria nacional (Rougier, 2006). El cambio sustancial de esta industria, al igual que en otros sectores manufactureros del país, se produjo con la apertura económica hacia finales de la década del 70 del siglo anterior. Se profundizó el proceso de extranjerización y el fuerte ingreso de equipos importados (García, 1999).

A partir del año 2002, se generó un cambio en la situación del sector comenzando un período de gran expansión signado por la depreciación de tipo de cambio real y un contexto internacional agrícola marcado por precios en ascenso. En este marco, se observó un incremento en la demanda, acompañada por un aumento en la oferta nacional. El análisis intrasectorial permite observar que las firmas de sembradoras y pulverizadoras continuaron con el gran dinamismo evidenciado en las décadas anteriores. La demanda es satisfecha casi en su totalidad localmente y la introducción de innovaciones tecnológicas es permanente (INDEC, 2012). En el caso de los tractores y cosechadoras, siguen teniendo una participación importante los equipos de origen extranjero. Estas importaciones corresponden, principalmente, a las firmas multinacionales que durante la década del 90 trasladaron sus filiales a otros países, en su mayoría a Brasil, manteniendo en el país solamente sus redes de distribución y servicios postventa (Langard, 2008; García, 2008). Ambos subsectores se encuentran dominados por las importaciones de las transnacionales John Deere, Case-New Holland y Agco Allis (Gutman et al., 2009). Específicamente en el rubro tractores, también existe un incremento en la producción nacional durante el período. Esto es el resultado, en la mayor parte de los casos, de la diversificación productiva de empresas con tradición en otros subsectores. Ahora bien, más allá de este cambio en la estructura productiva del sector, aun existen fuertes vacancias en la producción nacional de tractores por debajo de los $30 \mathrm{KW}$, destinados a producciones hortícolas u otras intensivas (Goering, 1992). Estos equipos no son producidos en el país, provocando una preponderancia en la utilización de equipos usados y en menor medida importados. Dado este contexto resulta interesante explorar el potencial mercado que podría tener una empresa dedicada a su fabricación, siendo el objetivo del presente trabajo estimar la demanda de un tractor de baja potencia en la Argentina. 